\title{
JAMALUDDIN AL-AFGHANI (PAN-ISLAMISME DAN IDE LAINNYA)
}

\author{
Ibrahim Nasbi \\ Universitas Islam Negeri Alauddin Makassar \\ ibrahim.nasbi@uin-alauddin.ac.id
}

\begin{abstract}
Abstrak: Jamaluddin al-Afghani (1838-1897 M) adalah salah seorang tokoh pembaru yang paling brilian dan pionir dalam menjawab tantangan Islam terhadap modernitas. Konsep-konsep pembaruan Afghani adalah Konsep-konsep pembaruan al-Afghani ialah; Pertama, musuh utama adalah penjajahan Barat yang merupakan kelanjutan dari perang salib; Kedua, umat Islam harus menentang penjajahan di mana dan kapan saja; Ketiga, untuk mencapai tujuan itu, umat Islam harus bersatu atau PanIslamisme. Pan-Islamisme merupakan ide pembaruan al-Afghani dalam bidang politik. Ide ini mengajarkan agar semua umat Islam seluruh dunia bersatu, untuk membebaskan mereka dari perbudakan asing. Bersatu bukan berarti leburnya kerajaan-kerajaan Islam menjadi satu, tapi mereka harus mempunyai satu pandangan hidup. Dalam pengertian yang luas, Pan-Islamisme berarti solidaritas antara seluruh muslim di dunia internasional. Tema perjuangan yang terus dikobarkan oleh al-Afghani dalam kesempatan apa saja adalah semangat melawan kolonialiasme dengan berpegang kepada tema-tema ajaran Islam sebagai stimulannya. Selain itu, beliau juga mengobarkan semangat untuk kembali ke teologi sunnatullah dengan pemikiran rasional, filosofis dan ilmiah guna mengejar ketertinggalan dari Barat.
\end{abstract}

Kata Kunci: Jamaluddin Al-Afghani; Pan Islamisme

\section{PENDAHULUAN}

Dalam perspektif historis, Islam dapat dibagi menjadi tiga periode besar; klasik, pertengahan dan modern. Masa Klasik (650-1250 M) merupakan zaman kemajuan yang terbagi dalam dua fase. Pertama, fase ekspansi, integrasi dan puncak kemajuan (650-1000 M). Kedua, fase disintegrasi (1000-1250 M) ketika Baghdad dihancurkan oleh Hulagu. Periode Pertengahan (1250-1800 M) juga dibagi dua tahap, yakni fase kemunduran ditandai dengan mengedepannya desentralisasi dan disintegrasi (1250-1500 M). Yang kedua, tiga kerajaan besar yang diawali oleh zaman kemajuan, (1500-1700 M) dan diakhiri di zaman kemunduran (1700-1800 M). Tiga kerajaan besar tersebut adalah Kerajaan 
Utsmani di Turki, Safawi di Persia dan Mughal di India. Episode yang terakhir dari periodisasi, ini adalah zaman modern (1800-sekarang). ${ }^{1}$

Era modern merupakan kondisi yang memprihatinkan bagi umat Islam. Sebagian besar dunia Islam dijajah oleh bangsa Eropa yang mengakibatkan jatuhnya Mesir dalam cengkeraman Barat. Hal ini menginsafkan dunia Islam akan kelemahannya dan menyadarkan bahwa di Barat telah timbul peradaban Baru yang lebih tinggi dan merupakan ancaman bagi Islam. ${ }^{2}$ Akhirnya timbullah ide-ide pembaruan dalam periode ini.

Ide-ide pembaruan itu berasal dari reduksi dan kajian secara intensif doktirin-doktrin Islam yang terdapat dalam al-Qur'an dan Hadis. Salah satu tokoh yang paling brilian dan pionir awal dalam menjawab tantangan modernitas itu ialah Jamaluddin al-Afghani.

Tulisan ini akan mengulas tentang tokoh pembaru ini dalam kaitannya dengan idenya mengenai Pan-Islamisme serta ide-ide pembaruan lainnya. Namun akan diawali dengan biografi singkat beliau guna memahami lebih muda ide-ide pembaruannya

\section{TINJAUAN TEORETIS}

\section{a. Biografi Jamaluddin Al-Afghani (1838-1897 M)}

Nama lengkapnya adalah Sayyid Jamaluddin al-Afghani bin Safar. Ia meupakan keturunan Sayyid Ali al-Tirmidzi, yang jika diruntut nasabnya akan sampai pada Husain bin Ali bin Abi Thalib. Hal ini tercermin dari gelar Sayyid yang disandangnya. ${ }^{3}$

Mengenai tempat lahirnya ada dua versi yang berbeda. Harun Nasution mengatakan bahwa ia lahir di Afghanistan 1839 dan wafat di Istanbul 1897. Sedangkan Nurcholish Madjid, Cyrill Glasse dan Jamil Ahmad mengatakan bahwa ia lahir di Asadabi, Iran (Persia). ${ }^{4}$

\footnotetext{
${ }^{1}$ Penjelasan secara mendetail dan komprehensif tentang periodisasi dapat dilihat dalam Harun Nasution, Pembaharuan dalam Islam: Sejarah Pemikiran dan Gerakan (Jakarta: Bulan Bintang, 1992), h. 12-14. Bandingkan dengan Antho Mudzhar, Pendekatan Sejarah Islam dalam Teori dan Praktek (Yogyakarta: Pustaka Pelajar, 1998), h. 22-23.

${ }^{2}$ Abdul Sani, Lintasan Sejarah Pemikiran: Perkembangan Modern dalam Islam, Ed. I; (Cet. I; Jakarta: PT. RajaGrafindo Persada, 1998), h. 41.

${ }^{3}$ Harun Nasution, Pembaharuan dalam Islam..., h. 51. Bandingkan dengan Jamil Ahmad, Hundred Great Muslims diterjemahkan oleh Putaka Furdaus dengan judul, Seratus Tokoh Muslim yang Terkemuka (Jakarta: Pustaka Firdaus, 1996), h. 269.

${ }^{4}$ Menurut pengakuannya, ia dilahirkan di Asadabi (Iran), meskipun pendapat lain menyebutkan nama kota yang sama tetapi di Afghanistan, di desa Konar. Hal ini merupakan wujud pengakuan politis agar ia selamat dari kesewenang-wenangan penguasa Persia yang tidak
} 
Pendidikan dan pengajaran dasarnya dari ayahnya sendiri, dari kecil sudah diajarkan mengaji al-Qur'an, besar sedikit lagi bahasa Arab dan sejarah. Ayahnya mendatangkan seorang guru ilmu Tafsir, Ilmu Hadis dan Ilmu Fiqih yang dilengkapi dengan ilmu Tasawwuf dan ke-Tuhan-an. ${ }^{5}$ Dengan intelegensi yang sangat luar biasa, dalam usia kurang lebih 18 tahun ia telah menguasai hampir semua cabang Ilmu Islam mulai ari filsafat, ushul fiqh, sejarah, metafisika, tasawwuf, kedokteran, sains, mistik sampai pada astronomi dan astrologi. Ia juga fasih berbahasa arab, Persia, Turki, Rustho, Inggris dan Rusia. ${ }^{6}$

Pengabdiannya yang pertama di Afghanistan adalah sebagai pembantu pangeran Dost Muhammad Khan di Afghanistan. Hal ini digelutinya ketika ia berusia 22 tahun. Kemudian menjadi penasehat Ali Khan pada tahun 1864 dan pada zaman pemerintahan Azam Khan diangkat menjadi Perdana Menteri. Pada masa ini, Inggris telah ikut campur dalam urusan politik dalam negeri Afghanistan. Dalam masa pergolakan ini, ia berpihak pada kelompok yang disokong Inggris. Akibat kekalahan kelompoknya, agar lebih aman, ia meninggalkan tanah kelahirannya dan menuju India pada tahun 1869 meskipun tidak lama di sana. ${ }^{7}$ Pada tahun 1870, ia pindah dan berdomisili di Turki, yang oleh Perdana Menteri Ali Pasha ia diangkat menjadi anggota Majelis Pendidikan Turki, kemudian pindah lagi ke Iran dan di sana di angkat menjadi Menteri Penerangan. ${ }^{8}$

Di tahun 1876, campur tangan Inggris dalam soal politik di Mesir makin meningkat. Untuk dapat bergaul dengan orang-orang politik di Mesir, ia memasuki perkumpulan Freemason Mesir. Kemudian untuk lebih memantapkan kepeduliannya terhadap kemelut politik-kenegaraan waktu itu, maka pada tahun 1879, ia membentuk partai al-Hizb al-Wathani (Partai Nasional). ${ }^{9}$

Selang beberapa bulan di Mesir, al-Afghani lantas melanglang buana ke Paris. Di negara ini, aktivitas politiknya meningkat dengan mendirikan perkumpulan al-

senang pada dirinya. Baca Tim Penyusun, Ensiklopedia Islam, Jilid II (Jakarta: Ichtiar Baru, 1999), h. 299. Juga Cyrill Glasse, The Consire Encyclopedia Islam diterjemahkan oleh Ghufran A. Mas'adi dengan judul: Ensiklopedi Islam (Riskas) (Jakarta: Rajawali Press, 1996), h. 13 serta Nurcholish Madjid (Ed), Khazanah Intelektual Islam (Jakarta: Bulan Bintang, 1994), h. 56.

${ }^{5}$ M. Yusran Asmuni, Aliran Modern dalam Islam: Mengenal Pokok-Pokok Pemikiran Para Pmukanya (Surabaya: al-Ikhlas, 1982), h. 42. 299

${ }^{6}$ Jamil Ahmad, Hundred Great Muslims h. 264. Juga Tim Penyusun, Ensiklopedia Islam., h.

${ }^{7}$ M. Yusran Asmuni, Aliran Modern dalam Islam., juga Abdul Sani, Lintasan Sejarah Pemikiran., h. 41; Harun Nasution, Pembaharuan dalam Islam..., h. 51

${ }^{8}$ M. Yusran Asmuni, Aliran Modern dalam Islam..., h. 42.

${ }^{9}$ Ide-ide al-Tahtawi sedang menjadi wacana publik ketika al-Afghani tiba di Mesir. Misalnya ide triaspolitica dan patriotisme. Pembentukan partai bertujuan untuk memperjuangkan pendidikan universal, kemerdekaan pers dan pemasukan unsur-unsur Mesir ke dalam posisi-posisi militer. Paparan selanjutnya baca Harun Nasution, Pembaharuan dalam Islam., h. 52. juga Abdul Sani, Lintasan Sejarah Pemikiran..., h. 42. 
Urwāt al-Wutsqa. Perkumpulan ini beranggotakan orang-orang Islam dari India, Mesir, Suria, Afrika Utara dan lain-lain. ${ }^{10}$

Pada tahun 1892, atas undangan Sultan Abdul Hamid, ia pindah ke Istanbul. Sultan Abdul Hamid bekerja sama dalam pemikiran-pemikiran demokratis al-Afghani dalam bidang pemerintahan. Namun kerja sama ini tidak bisa tercapai sepenuhnya, karena Sultan masih ingin mempertahankan kekuasaan otokrasi. Akibat pengaruh al-Afghani yang begitu besar, maka Sultan merasa takut. Akhirnya, kebebasan al-Afghani dibatasi dan ia tidak dapat keluar dari Istanbul sampai ia wafat tahun $1897 .{ }^{11}$

\section{b. Ide-Ide Pembaruan Jamaluddin Al-Afghani}

Berangkat dari paparan di atas, maka dapat dikatakan bahwa kegiatan yang banyak menyita perhatian al-Afghani adalah kegiatan politik. Oleh karena itu, alAfghani lebih banyak bersifat pemimpin politik daripada pemimpin dan pemikir pembaruan dalam Islam.

Dalam bahasa L. Stoddard, al-Afghani lebih banyak memikirkan masalah politik daripada masalah keagamaan. ${ }^{12}$ Sementara itu, Ignaz Goldziher memandang al-Afghani sebagai tokoh politik dan bukan sebagai pembaru dalam persoalan agama. ${ }^{13}$

Pernyataan dari kedua tokoh di atas tidak dapat serta merta diterima, karena keseriusan dan kesungguhan al-Afghani dalam dunia politik, berangkat dari motivasi agama. Kepedulian al-Afghani pada politik sekaligus menghapus anggapan dunia Barat tentang tokoh Islam yang hanya intens terhadap agama tanpa peduli dengan bidang lain.

Konsep-konsep pembaruan al-Afghani ialah; Pertama, musuh utama adalah penjajahan Barat yang merupakan kelanjutan dari perang salib; Kedua, umat Islam harus menentang penjajahan di mana dan kapan saja; Ketiga, untuk mencapai tujuan itu, umat Islam harus bersatu atau Pan-Islamisme. ${ }^{14}$

Pan-Islamisme ${ }^{15}$ merupakan ide pembaruan al-Afghani dalam bidang politik. Ide ini mengajarkan agar semua umat Islam seluruh dunia bersatu, untuk

\footnotetext{
${ }^{10}$ Abdul Sani, Lintasan Sejarah Pemikiran..., h. 43.

${ }^{11}$ Abdul Sani, Lintasan Sejarah Pemikiran..., h. 43

${ }^{12}$ L. Stoddard, The New World of Islam, diterjemahkan oleh Sidi Gazalba dkk. dengan judul: Dunia Baru Islam (Jakarta: tp, 1996), h. 61

${ }^{13}$ Harun Nasution, Pembaharuan dalam Islam., h. 54.

${ }^{14}$ M. Yusran Asmuni, Aliran Modern dalam Islam..., h. 42-43.

${ }^{15}$ Pan Islamisme (Yunani, pan atau pas = semua) adalah gagasan yang karena Islam merupakan kesatuan, menyatakan bahwa semua umat Muslim harus bersatu menghadapi dominasi Barat. Istilah ini bercorak politik dan diberikan oleh para pengamat Barat terhadap gagasan
} 
membebaskan mereka dari perbudakan asing. ${ }^{16}$ Bersatu bukan berarti leburnya kerajaan-kerajaan Islam menjadi satu, tapi mereka harus mempunyai satu pandangan hidup. ${ }^{17}$

Dalam pengertian yang luas, Pan-Islamisme berarti solidaritas antara seluruh muslim di dunia internasional. Tema perjuangan yang terus dikobarkan oleh al-Afghani dalam kesempatan apa saja adalah semangat melawan kolonialiasme dengan berpegang kepada tema-tema ajaran Islam sebagai stimulannya. ${ }^{18}$

Murtadha Muthahhari menjelaskan bahwa diskursus tema-tema itu antara lain di seputar; perjuangan melawan absolutisme para penguasa, melengkapi sains dan teknologi modern, kembali kepada ajaran Islam yang sebenarnya, iman dan keyakinan akidah, perjuangan melawan kolonial asing, persatuan Islam, menginsafkan semanghat perjuangan dan perlawanan ke dalam tubuh masyarakat yang sudah separoh mati dan perjuangan melawan ketakutan terhadap Barat. ${ }^{19}$

Gerakan Pan-Islamisme menegaskan kembali landasan-landasan umat Muslim dalam pengertian Nasionalisme. Dalam perspektif politik, Pan-Islamisme dimaksudkan untuk menentang penetrasi Eropa, tetapi Pan-Isalmisme juga mengandung aspek reformasi internal. Dengan penuh kegigihan, al-Afghani menyerang penyalahgunaan-penyalahgunaan Islam yang dilihatnya dan kejahatan-kejahatan yang dilakukan oleh pemerintah-pemerintah Islam. Inti pokok pemikirannya adalah membawa umat Islam harus membersihkan diri mereka sendiri dari kesalahan-kesalahan dan pencampuaradukkan agama. Para ulama harus tampil maju menghadapi arus-arus pemikiran modern, dan negara Islam harus tampil sebagai ekspresi politik dan sarana untuk menyuarakan ajaran-ajaran ortodoksi Alquran. ${ }^{20}$

Persatuan Islam hanya dapat dicapai apabila berada dalam kesatuan pandangan dan kembali kepada ajaran Islam yang murni (Alquran dan alHadis). ${ }^{21}$ Dengan kata lain, umat Islam harus mampu menangkap kembali ajaran agamanya yang lebih dinamis, sekaligus lebih otentik. Atau, dalam bahasa slogan

Jamaluddin al-Afghani. Tetapi Afghani sendiri menyebut gagasannya sebagai Jami'ah Islamiyyah dan bercorak moral. Lihat H.A.R. Gibb, Modern Trends in Islam, diterjemahkan oleh Machnun Husein dengan judul: Aliran-Aliran Modern dalam Islam (Cet. V; Jakarta: RajaGrafindo Persada, 1995), h. 49.

${ }^{16}$ Oemar Amin Hoesin, Filsafat Islam (Cet. III; Jakarta: Bulan Bintang, 1975), h. 164.

${ }^{17}$ M. Yusran Asmuni, Aliran Modern dalam Islam..., h. 43.

${ }^{18}$ Munthoha ... (et.al), Pemikiran dan Peradaban Islam (Cet. I; Yogyakarta: UII-Press, 1998), h. 105.

${ }^{19}$ Murtadha Muthahhari, Gerakan Islam Abad XX (terjemahan) (Jakarta: Rineka Cipta, 1986), h. 106.

${ }^{20}$ H.A.R. Gibb, Modern Trends in Islam., h. 49

${ }^{21}$ Murtadha Muthahhari, Gerakan Islam Abad XX., h. 106 
Bung Karno, umat mampu menangkap "api Islam”, dan meninggalkan abunya, sebagaimana dicerminkan dalam sejarah klasiknya yang gemilang selama berabad-abad. $^{22}$

Ide ini berangkat dari kondisi umat Islam yang sedang mengalami kemunduran. Kemunduran umat Islam bukanlah karena Islam, apalagi kalau menganggap Islam tidak sesuai dengan perubahan zaman dan kondisi baru. Umat Islam mundur menurutnya karena telah meninggalkan ajaran-ajaran Islam sebenarnya dan mengikuti ajaran-ajaran yang datang dari luar Islam lagi asing bagi Islam. Ajaran-ajaran asing itu dibawa oleh orang-orang yang pura-pura bersikap suci. Atau orang-orang yang mempunyai keyakinan-keyakinan yang menyesatkan dan oleh hadis-hadis buatan. Misalnya, paham qadha dan qadar. Paham ini telah dirusak dan diubah menjadi fatalisme yang membawa umat Islam kepada keadaan statis. Ajaran Islam yang murni tinggal di bibir dan di atas kertas. $^{23}$

Al-Afghani menolak ajaran qadhā' dan qadhar yang mengandung paham fatalistik. Menurut pendapatnya, qadhō' dan qadar mengandung arti bahwa segala sesuatu terjadi menurut ketentuan sebab akibat. Qadhā' dan qadar, menurutnya, sama dengan hukum alam ciptaan Tuhan. ${ }^{24}$

Selain itu, kemunduran umat Islam disebabkan oleh lemahnya persaudaraan Islam. Nilai-nilai persaudaraan umat Islam telah terputus, bukan hanya dikalangan orang awam saja, tetapi juga dikalangan alim-ulama. Usaha memperbaiki umat Islam, menurut al-Afghani ialah dengan cara melenyapkan pemahaman keliru yang dianut umat pada umumnya, dan kembali kepada ajaran Islam yang sebenarnya. ${ }^{25}$

Di atas segala-galanya persatuan umat Islam mesti diwujudkan kembali. Umat Islam akan memperoleh kembali kemajuan apabila mereka bersatu dan melakukan kerja sama yang intim. Persatuan dan kerja sama adalah pilar yang sangat urgen dalam Islam. Inilah makna kerja sama yang merupakan bentuk solidaritas tertinggi kaum muslimin yang sementara ini menurutnya telah terpecah belah akibat ketidakbecusan para penguasa. Dengan kata lain, alAfghani masih menganggap agama sebagai alat pemersatu yang paling kuat. ${ }^{26}$

Selain itu, ide ini didasari atas justifikasi negara-negara Barat atas penyerangan dan kekejaman yang dilakukan kepada negara-negara Timur.

\footnotetext{
${ }^{22}$ Nurcholish Madjid, Kaki Langit Peradaban (Cet. I; Jakarta: Paramadina, 1997), h. 22.

${ }^{23}$ Abdul Sani, Lintasan Sejarah Pemikiran: Perkembangan Modern dalam Islam, h. 43

${ }^{24}$ Harun Nasution, Islam Rasional: Gagasan dan Pemikiran (Cet. IV; Bandung: Mizan, 1996), h. 150

${ }^{25}$ Harun Nasution, Islam Rasional: Gagasan dan Pemikiran h. 46.

${ }^{26}$ Harun Nasution, Islam Rasional: Gagasan dan Pemikiran, h. 46.
} 
Kemudian Barat telah menggunakan segala daya untuk mencegah tumbuhnya kekuatan negara-negara Timur. Segala gejala yang membawa kepada kemajuan dari negeri Islam, ditumpas habis dengan segala kekuatan, walaupun dengan jalan perang sekali pun. ${ }^{27}$

Oleh karena itu, al-Afghani menyerukan agar segenap negeri Islam perlu bersatu dalam suatu pertahanan bersama guna membela kedudukan mereka dan dari keruntuhannya. Untuk mencapai hal tersebut, umat Islam harus mempunyai kepandaian teknik dalam kemajuan Barat dan wajib mempelajari rahasia kekuatan orang Eropa. ${ }^{28}$

Selain itu, cara lain yang perlu ditempuh untuk memajukan dunia Islam dan mengejar ketinggalan dari Barat, menurut al-Afghani, ${ }^{29}$ adalah kembali ke teologi sunnatullah dengan pemikiran rasional, filosofis dan ilmiah. Kepercayaan kepada sunnatullah akan membawa kepada pemikiran ilmiah dan sikap dinamis. Menurutnya, sains yang berkembang dengan pesat di Eropa, perlu dikuasai kembali oleh ulama dan kaum terpelajar Islam. ${ }^{30}$

Ide lain dari pembaruan al-Afghani adalah pernyataan beliau yang mengatakan bahwa pintu ijtihad tidak pernah tertutup dan tidak ada orang yang bisa menutupnya. Reinterpretasi ajaran-ajaran al-Qur'an dan Hadis agar sesuai dengan zaman modern hanya bisa dilakukan melalui ijtihad. ${ }^{31}$

Ide-ide ini dituangkan dalam tulisan-tulisannya yang dipublikasikan dalam majalah al-Urwāt al-Wutsqa. Dalam sebuah tulisannya yang berjudul "Persatuan Islam", ia mengatakan: "Umat Islam pernah bersatu dalam kesatuan umat di bawah pemerintahan yang gilang gemilang. Pada masa itu, umat Islam mencapai kemajuan dalam ilmu dan sains. Mereka terkemuka di bidang filsafat dan ilmuilmu yang lain. Apa yang kita capai pada waktu itu kini menjadi pusaka dan kebanggan umat Islam sampai sekarang. Umat Islam harus sadar bahwa dalam keadaan apa pun, mereka tidak boleh berdamai dan bekerja sama dengan orang yang menjajah mereka." 32

Orang-orang Eropa, yang rakus dan tamak terhadap negeri-negeri kaum Muslim berusaha memecahkan persatuan umat Islam dan mengambil keuntungan dari perpecahan itu. Pikiran yang membenarkan umat Islam berpecah, bukanlah

${ }^{27}$ Oemar Amin Hoesin, Filsafat Islam, h. 164.

${ }^{28}$ Ibid.,

${ }^{29}$ Selain Al-Afghani, pemikir lain yang sama idenya dalam hal ini adalah Muhammad Abduh di Mesir, Zia Gokalp di Turki dan Sayyid Ahmad Khan di India. Harun Nasution, Islam Rasional...., loc. cit., h. 119.

${ }^{30}$ Harun Nasution, Islam Rasional....., h. 149.

${ }^{31}$ Harun Nasution, Islam Rasional...., h. 119.

${ }^{32}$ Oemar Amin Hoesin, Filsafat Islam, h. 164. 
pikiran Islam, tetapi pikiran yang dihembuskan dari luar kedalam otak kaum Muslim oleh musuh-musuhnya. ${ }^{33}$

Dengan kata lain, untuk mencapai ide-idenya, al-Afghani mengusahakan dalam wacana:

1) Rakyat harus dibersihkan dari kepercayaan ketahayulan.

2) Orang harus yakin bahwa ia dapat mencapai tingkat/derajat budi luhur.

3) Rukun Iman harus menjadi harus betul-betul menjadi pegangan hidup dalam kehidupan manusia, bukan sekedar ikutan belaka.

4) Setiap generasi umat harus ada lapisan istimewa untuk memberikan pendidikan dan pengajaran pada manusia-manusia yang bodoh dan juga memerangi hawa nafsu jahat dan menegakkan disiplin. ${ }^{34}$

Demikianlah, sekilas tentang sosok dan ide pemikiran pembaruan alAfghani yang berintikan Pan-Islamisme (persatuan umat Islam). Semasa hidupnya, al-Afghani berusaha untuk mewujudkan persatuan itu yang sedikitbanyaknya membuahkan hasil. Hal ini terlihat jelas dalam ide-ide modernisme di Mesir yang menggugah kesadaran umat Islam untuk mengevalusi diri terutama pada hal-hal yang berkenaan dengan keterbelakangan yang mereka hadapi. ${ }^{35}$

Selain di Mesir, ide-ide al-Afghani, juga mempengaruhi pemikir-pemikir pembaru sesudahnya. Di Turki misalnya, pada akhir abad ke 19, Abdul Hamid, Sultan Turki, melancarkan program Pan-Islamisme. Program ini dimaksudkan untuk menyelamatkan rezimnya yang goyah akibat serangan dari luar dan tumbuhnya gerakan nasionalisme dari dalam. Beberapa tahun kemudian, semangat Pan-Islamisme timbul di kalangan umat Islam di India. ${ }^{36}$

Dengan kata lain, pemikiran al-Afghani mempunyai arti yang sangat signifikan dalam dunia Islam. Signifikansi ini terletak pada daya jangkauan pemikiran al-Afghani yang "multinasional". Selain itu, umat Islam benar-benar merasa tercambuk untuk menyadari atas perlunya gerakan fisik material dan intelek-spiritual dalam membangun kembali obsesi kemajuan peradabannya. ${ }^{37}$

Hamka, menilai Jamaluddin al-Afghani laksana seekor Rajawali yang selalu memiliki wawasan yang tajam, cemerlang dan sangat ditakuti lawan. "Sang Rajawali" tidak pernah memiliki sarang rendah, tempatnya pun selalu berpindah-pindah. Wibawanya terpancar dari kekuatan mata yang siap melumpuhkan lawan. ${ }^{38}$

${ }^{33}$ Oemar Amin Hoesin, Filsafat Islam, h. 165.

${ }^{34}$ M. Yusran Asmuni, Aliran Modern dalam Islam..., h. 43.

${ }^{35}$ Abdul Sani, Lintasan Sejarah Pemikiran: Perkembangan Modern dalam Islam, h. 47.

${ }^{36}$ A. Mukti Ali, Alam Pikiran Islam Modern di India dan Pakistan (Cet. IV; Bandung: Mizan, 1998), h. 38-39.

${ }^{37}$ Abdul Sani, Lintasan Sejarah Pemikiran: Perkembangan Modern dalam Islam, h. 47.

${ }^{38}$ Hamka, Jamaluddin al-Afghani (Jakarta: Bulan Bintang, 1970. 
Cahaya pembaruan yang dipancarkan "Sang Rajawali", sanggup menyinari hampir seluruh wilayah Islam, bahkan sampai ke Indonesia. ${ }^{39}$ Inilah mata rantai dan anak tangga yang sangat urgen, menuju bangunan peradaban Islam dalam konteks kekinian.

\section{PENUTUP}

\section{a. Kesimpulan}

1) Jamaluddin al-Afghani adalah seorang modernis, pembaru, dan revolusioner politik yang sangat concern dengan solidaritas Islam (PanIslamisme)

2) Untuk mencapai ide-idenya, al-Afghani mengusahakan dalam wacana:

3) Rakyat harus dibersihkan dari kepercayaan ketahayulan.

4) Orang harus yakin bahwa ia dapat mencapai tingkat/derajat budi luhur.

5) Rukun Iman harus menjadi harus betul-betul menjadi pegangan hidup dalam kehidupan manusia, bukan sekedar ikutan belaka.

6) Setiap generasi umat harus ada lapisan istimewa untuk memberikan pendidikan dan pengajaran pada manusia-manusia yang bodoh dan juga memerangi hawa nafsu jahat dan menegakkan disiplin.

\section{DAFTAR PUSTAKA}

Nasution, Harun., Pembaharuan Dalam Islam: Sejarah Pemikiran dan Gerakan Jakarta: Bulan Bintang, 1992.

Nasution, Harun., Islam Rasional: Gagasan dan Pemikiran Cet. IV; Bandung: Mizan, 1996

Mudzhar, Antho., Pendekatan Sejarah Islam dalam Teori dan Praktek Yogyakarta: Pustaka Pelajar, 1998.

Sani, Abdul., Lintasan Sejarah Pemikiran: Perkembangan Modern dalam Islam, Ed. I; Cet. I; Jakarta: PT. RajaGrafindo Persada, 1998.

Ahmad, Jamil., Hundred Great Muslims diterjemahkan oleh Putaka Furdaus dengan judul, Seratus Tokoh Muslim yang Terkemuka Jakarta: Pustaka Firdaus, 1996.

Tim Penyusun, Ensiklopedia Islam, Jilid II Jakarta: Ichtiar Baru, 1999.

\footnotetext{
${ }^{39}$ Pemikiran tokoh tersebut, banyak berpengaruh kepada tidak sedikit tokoh-tokoh Indonesia seperti, Mas Mansur, Abdul Kahhar Muzakir, Farid MA'ruf, Muh. Rosydi, KH. Ahmad Dahlan, KH. Hasyim al-Asyari dan Hamka. Baca misalnya Alwi Shihab, Islam Mistik, Islam Pertama dan Pengaruhnya Hingga Kini di Indonesia (Bandung: Mizan, 2001), h. 204.
} 
Glasse, Cyrill., The Consire Encyclopedia Islam diterjemahkan oleh Ghufran A. Mas'adi dengan judul: Ensiklopedi Islam (Riskas) Jakarta: Rajawali Press, 1996.

Madjid, Nurcholish (Ed), Khazanah Intelektual Islam Jakarta: Bulan Bintang, 1994. ., Kaki Langit Peradaban Cet. I; Jakarta: Paramadina, 1997.

Asmuni, M. Yusran., Aliran Modern Dalam Islam: Mengenal Pokok-Pokok Pemikiran Para Pmukanya Surabaya: al-Ikhlas, 1982.

Stoddard, L., The New World of Islam, diterjemahkan oleh Sidi Gazalba dkk. dengan judul: Dunia Baru Islam Jakarta: tp, 1996.

Gibb, H.A.R., Modern Trends in Islam, diterjemahkan oleh Machnun Husein dengan judul: Aliran-Aliran Modern dalam Islam Cet. V; Jakarta: RajaGrafindo Persada, 1995.

Hoesin, Oemar Amin., Filsafat Islam Cet. III; Jakarta: Bulan Bintang, 1975.

Munthoha ... (et.al), Pemikiran dan Peradaban Islam Cet. I; Yogyakarta: UIIPress, 1998.

Muthahhari, Murtadha., Gerakan Islam Abad XX (terjemahan) Jakarta: Rineka Cipta, 1986.

Nasution, Harun., Islam Rasional: Gagasan dan Pemikiran Cet. IV; Bandung: Mizan, 1996.

Ali, A. Mukti., Alam Pikiran Islam Modern di India dan Pakistan Cet. IV; Bandung: Mizan, 1998.

Hamka, Jamaluddin al-Afghani Jakarta: Bulan Bintang, 1970.

Shihab, Alwi., Islam Mistik, Islam Pertama dan Pengaruhnya Hingga Kini di Indonesia Bandung: Mizan, 2001. 